\title{
Revérification de l'élimination de la rougeole, de la rubéole et du syndrome de rubéole congénitale, 2016 à 2020
}

\author{
Myriam Saboui ${ }^{1 *}$, Joanne Hiebert ${ }^{2}$, Susan G Squires ${ }^{1}$, Mireille Guay ${ }^{3}$, Patricia Barcellos ${ }^{4}$, \\ Alan Thom ${ }^{4}$, Y Anita $\mathrm{Li}^{1}$
}

Citation proposée : Saboui M, Hiebert J, Squires SG, Guay M, Barcellos P, Thom A, Li YA. Revérification de I'élimination de la rougeole, de la rubéole et du syndrome de rubéole congénitale, 2016 à 2020. Relevé des maladies transmissibles au Canada 2021;47(11):528-30. https://doi.org/10.14745/ccdr.v47i11a06f

Mots-clés : rougeole, rubéole, embryopathie rubéolique, élimination, surveillance, santé publique

\section{Introduction}

L'élimination, dans le contexte de la rougeole, de la rubéole et du syndrome de rubéole congénitale, désigne l'absence de transmission endémique du virus de la rougeole/rubéole dans une région ou une autre zone géographique définie pendant au moins 12 mois, en présence d'un système de surveillance de haute qualité qui atteint les cibles des indicateurs de rendement clés. En 1994, le Canada et les autres pays de la région des Amériques de l'Organisation mondiale de la Santé (OMS) se sont engagés à atteindre les objectifs d'élimination de la rougeole par l'an 2000 et de la rubéole et du syndrome de rubéole congénitale par l'an 2010. Le Canada a atteint ces objectifs : élimination de la transmission de la rougeole en 1998, de la rubéole en 2005 et du syndrome de rubéole congénitale d'origine endémique en 2000. La région des Amériques de l'OMS a été déclarée exempte de rubéole/de syndrome de rubéole congénitale endémique en 2015 et de rougeole endémique en 2016.

À la demande de l'Organisation panaméricaine de la santé, le statut d'élimination de la rougeole, de la rubéole et du syndrome de rubéole congénitale du Canada a été vérifié en 2012, puis à nouveau en 2017. Avant d'être soumis à l'Organisation panaméricaine de la santé, les rapports de vérification ont été passés en revue, approuvés et avalisés par le Comité national de certification du Canada. Le Comité national de certification est un groupe d'experts qui ne participent pas directement à la gestion des maladies évitables par la vaccination ou à la mise en œuvre des programmes d'immunisation à l'échelle nationale, mais qui possèdent l'expertise nécessaire pour aider à faire en sorte que le Canada atteigne les objectifs d'élimination et d'éradication de l'Organisation panaméricaine de la santé. Les membres sont chargés d'examiner les mécanismes actuels de surveillance du Canada et les progrès réalisés en vue de l'élimination des maladies évitables ciblées par la vaccination au Canada. Les membres ont une expertise dans les domaines de la santé publique, des maladies infectieuses et/ou des sciences de laboratoire.
Cette oeuvre est mise à la disposition selon les termes de la licence internationale Creative Commons Attribution 4.0

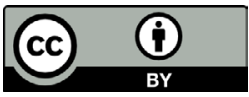

Affiliations

${ }^{1}$ Division de la surveillance de la santé et de l'épidémiologie, Centre de l'immunisation et des maladies respiratoires infectieuses, Agence de la santé publique du Canada, Ottawa, ON

${ }^{2}$ Laboratoire national de microbiologie, Agence de la santé publique du Canada, Winnipeg, MB

${ }^{3}$ Division de la surveillance de la couverture et de l'efficacité des vaccins, Agence de la santé publique du Canada, Ottawa, ON

${ }^{4}$ Division du programme d'immunisation, Centre de préparation à l'immunisation, Agence de la santé publique du Canada, Ottawa, ON

\section{*Correspondance :}

myriam.saboui@phac-aspc.gc.ca

\section{Situation actuelle}

Au début du mois de janvier 2021, le Canada a reçu une notification de l'Organisation panaméricaine de la santé demandant un rapport national présentant des analyses de données actualisées relatives à la durabilité de l'élimination de la rougeole, de la rubéole et du syndrome de rubéole congénitale pour la période de 2016 à 2020. Un modèle a été fourni par l'Organisation panaméricaine de la santé à partir d'une série d'indicateurs et de questions portant sur cinq domaines principaux : épidémiologie des maladies, qualité de la surveillance, surveillance en laboratoire, analyse de la population de la cohorte, y compris la couverture vaccinale, et la durabilité.

Dans le cadre de cette demande, le Comité national de certification a été appelé à examiner le rapport intitulé Revérification de l'élimination de la rougeole, de la rubéole et du syndrome de rubéole congénitale, 2016-2020 (1). Plus précisément, le Comité national de certification a examiné les éléments de preuve et a déterminé si le rassemblement des éléments de preuve répondait aux questions suivantes : 
1. Le Canada a-t-il maintenu l'élimination de la rougeole, de la rubéole et du syndrome de rubéole congénitale depuis que la Région des Amériques a été déclarée région exempte de ces maladies en 2016 et 2015 , respectivement?

2. Le Canada est-il prêt à demander une nouvelle vérification de l'élimination de la rougeole et/ou de la rubéole s'il a établi qu'il y avait eu une transmission endémique de l'une de ces deux maladies?

Le rapport a été préparé par le Centre de l'immunisation et des maladies respiratoires infectieuses et le Laboratoire national de microbiologie, avec la contribution du Centre de préparation à l'immunisation COVID-19 (COVID-19; maladie à coronavirus 2019) et du Centre de surveillance des vaccins contre la COVID-19 de l'Agence de la santé publique du Canada. Le rapport et les documents à l'appui ont été approuvés par le ministre de la Santé du Canada au début du mois de mai, puis avalisés par le Comité national de certification. Le Canada a soumis le rapport approuvé par le Comité national de certification, ainsi que les documents à l'appui, à l'Organisation panaméricaine de la santé le 14 juin 2021, comme demandé.

\section{Résultats}

Entre 2016 et 2020, 199 cas de rougeole, deux cas de rubéole et un cas de syndrome de rubéole congénitale ont été signalés au Canada (tableau 1). Le nombre de cas de rougeole déclaré a varié annuellement entre 1 cas et 113 cas, avec un seul cas déclaré en 2020_avant le début de la pandémie de COVID-19. Un peu plus de femmes que d'hommes ont été touchées par la rougeole $(n=111 / 199)$. Parmi les cas où le statut vaccinal était disponible, $53 \%$ n'étaient pas vaccinés, contre $46 \%$ des cas dont la vaccination était à jour. Parmi les cas de rougeole déclarés, 80 (40\%) étaient importés. Dix-neuf éclosions de rougeole ont été déclarés. L'âge médian des cas d'éclosion de rougeole était de 17 ans (étalé de 0 à 58 ans). La majorité des cas index $(n=17)$ ont déclaré avoir voyagé à l'extérieur du Canada pendant leur période d'incubation. Les deux autres cas index comprenaient un cas qui n'avait pas voyagé à l'extérieur du Canada, mais qui a été potentiellement exposé à un cas international dans un port canadien et un cas qui n'a pas déclaré de voyage à l'extérieur du Canada ou d'exposition à un voyageur. Des souches de rougeole de génotypes B3 et D8 ont été détectées au Canada entre 2016 et 2020, la souche de génotype D8 nommée MVs/Gir Somnath.IND/42.16/ ayant été signalée tout au long de 2019.

\section{Conclusion}

Les données épidémiologiques et virologiques présentées dans le rapport confirment que le Canada a maintenu l'élimination de la rougeole, de la rubéole et du syndrome de rubéole congénitale depuis que la région des Amériques de l'OMS a
Tableau 1 : Critères essentiels de l'Organisation panaméricaine de la santé pour la vérification de l'élimination de la rougeole

\begin{tabular}{|c|c|c|}
\hline Critère $^{a}$ & Indicateur & Description \\
\hline $\begin{array}{l}\text { Vérifier } \\
\text { l'interruption des } \\
\text { cas endémiques } \\
\text { de rougeole } \\
\text { pendant une } \\
\text { période d'au } \\
\text { moins trois ans à } \\
\text { partir du dernier } \\
\text { cas endémique } \\
\text { connu, en } \\
\text { présence d'une } \\
\text { surveillance de } \\
\text { qualité. }\end{array}$ & $\begin{array}{l}\text { Aucun cas de } \\
\text { transmission } \\
\text { endémique. }\end{array}$ & $\begin{array}{l}\text { Au total, } 199 \text { cas de rougeole, } \\
\text { deux cas de rubéole et un } \\
\text { cas de syndrome de rubéole } \\
\text { congénitale ont été déclarés } \\
\text { entre } 2016 \text { et } 2020 \text {. Voici la } \\
\text { répartition des cas de rougeole } \\
\text { par source de transmission : } \\
\text { Hors du Canada }: n=80 \\
\text { Au Canada }: n=94 \\
\text { Au Canada, lié à un cas/une } \\
\text { chaîne d'origine inconnue : } \\
n=11 \\
\text { Source inconnue }: n=14\end{array}$ \\
\hline $\begin{array}{l}\text { Maintenir une } \\
\text { surveillance de } \\
\text { haute qualité et } \\
\text { suffisamment } \\
\text { sensible pour } \\
\text { détecter les cas } \\
\text { importés et liés à } \\
\text { l'importation. }\end{array}$ & $\begin{array}{l}\text { Plus de } \\
\text { deux cas } \\
\text { soupçonnés } \\
\text { pour } 100000 \\
\text { habitants } \\
\text { de manière } \\
\text { adéquate. }\end{array}$ & $\begin{array}{l}\text { Le Canada n'enquête pas sur les } \\
\text { cas soupçonnés de rougeole, } \\
\text { de rubéole ou de syndrome de } \\
\text { rubéole congénitale. Le critère } \\
\text { est rempli pour les cas confirmés } \\
\text { en laboratoire. }\end{array}$ \\
\hline $\begin{array}{l}\text { Vérifier l'absence } \\
\text { de souches } \\
\text { endémiques } \\
\text { du virus de la } \\
\text { rougeole par } \\
\text { la surveillance } \\
\text { virale. }\end{array}$ & $\begin{array}{l}\text { Génotype de } \\
\text { la rougeole } \\
\text { évalué dans } \\
80 \% \text { des cas }\end{array}$ & $\begin{array}{l}\text { Un génotype et une lignée } \\
\text { ont été identifiés pour } 100 \% \\
\text { ( } n=20 / 20 \text { ) des éclosions de } \\
\text { rougeole. } \\
\text { Aucune éclosion de rubéole } \\
\text { n'a eu lieu, bien que deux cas } \\
\text { sporadiques soient apparus, } \\
\text { avec des renseignements sur le } \\
\text { génotype pour l'un d'entre eux. }\end{array}$ \\
\hline $\begin{array}{l}\text { Vérifier } \\
\text { l'immunisation } \\
\text { adéquate de la } \\
\text { population. }\end{array}$ & $\begin{array}{l}95 \% \text { des } \\
\text { cohortes de } \\
\text { population } \\
\text { âgées de } 1 \\
\text { à } 40 \text { ans ont } \\
\text { reçu un vaccin } \\
\text { contenant la } \\
\text { rougeole. }\end{array}$ & $\begin{array}{l}\text { Le Canada mesure actuellement } \\
\text { (tous les deux ans) les taux de } \\
\text { couverture vaccinale contre la } \\
\text { rougeole à l'âge de deux et sept } \\
\text { ans, et n'est donc pas en mesure } \\
\text { d'évaluer la couverture vaccinale } \\
\text { contre la rougeole pour tous les } \\
\text { âges de } 1 \text { à } 40 \text { ans. L'enquête } \\
\text { nationale sur la couverture } \\
\text { vaccinale des enfants de } 2019 \\
\text { a estimé à } 90 \% \text { la couverture } \\
\text { vaccinale de la première dose } \\
\text { contenant la rougeole chez les } \\
\text { enfants de deux ans. }\end{array}$ \\
\hline
\end{tabular}

été déclarée région exempte de ces maladies en 2016 et 2015, respectivement. Malgré l'élimination de la rougeole, de la rubéole et du syndrome de rubéole congénitale, des cas et des éclosions ont été signalés au Canada au cours des cinq dernières années. Cette tendance devrait se poursuivre jusqu'à ce que la circulation de ces virus soit éliminée dans toutes les régions de l'Organisation mondiale de la santé. Les Canadiens qui voyagent à l'étranger doivent continuer à s'assurer que leurs vaccinations contre la rougeole et la rubéole sont à jour. Les professionnels de la santé doivent rester attentifs aux symptômes de la rougeole et de la rubéole, d'autant plus que les restrictions aux voyages internationaux liées à la COVID-19 commencent à s'alléger. Le 
Canada reste déterminé à éliminer la rougeole et la rubéole; il est donc essentiel de poursuivre la surveillance épidémiologique, y compris les tests de laboratoire sur les cas soupçonnés de rougeole et de rubéole.

\section{Déclaration des auteurs}

M. S. - Conceptualisation, méthodologie, logiciel, analyse formelle, enquête, conservation des données, rédaction-version originale, rédaction-révision et édition, visualisation J. H. - Méthodologie, analyse formelle, rédaction-version originale, rédaction-révision et édition

S. G. S. - Conceptualisation, écriture-révision et édition

M. G. - Rédaction-révision et édition

P. B. - Rédaction-révision et édition

A. T. - Rédaction-révision et édition

Y. A. L. - Méthodologie, révision et édition

\section{Intérêts concurrents}

Aucun.

\section{Remerciements}

Les auteurs remercient les provinces et les territoires d'avoir fourni des données au Système canadien de surveillance de la rougeole et de la rubéole et les membres du Comité national de certification, le Dr lan Gemmill, la Dre Joanne Embree et le Dr Todd Hatchette, pour le temps et l'expertise qu'ils ont consacrés à l'examen et à l'approbation du rapport Revérification de l'élimination de la rougeole, de la rubéole et du syndrome de rubéole congénitale au Canada, 2016-2020.

\section{Financement}

Ce travail a été soutenu par l'Agence de santé publique du Canada.

\section{Références}

1. National Certification Committee (Canada). Re-verification of the Elimination of Measles, Rubella and Congenital Rubella Syndrome (CRS) Elimination, 2016-2020. (Document non publié)

2. Pan American Health Organization. Measles elimination in the Americas. https://www3.paho.org/hq/index. php?option=com_content\&view=article\&id=12526: measleselimination-in-the-americas\&ltemid=40721\&lang=en 